\title{
O PAPEL DA MONITORIA DE MATEMÁTICA NA APRENDIZAGEM DE PESSOAS COM DEFICIÊNCIA VISUAL
}

\section{THE ROLE OF MATHEMATICAL MONITORING IN THE LEARNING OF PERSONS WITH VISUAL DEFICIENCY}

\author{
Thiago dos Santos Bezerra ${ }^{1}$; Leandro da Costa Silva ${ }^{2}$; Antonio Carlos Vicente Figueredo ${ }^{3}$; \\ Vanessa Gosson Gadelha De Freitas Fortes ${ }^{4}$
}

\section{INTRODUÇÃO}

Embora haja muitos esforços para que a inclusão se consolide nas escolas brasileiras, ela ainda é muito precária. Poucas instituições de ensino dispõem de um aparato que possibilitem a recepção, de forma adequada, de alunos com necessidades educacionais específicas. Isso se torna algo contraditório para o país, uma vez que a Constituição Federal de 1988 (a lei maior do país), em seu artigo 205, diz que a educação é um direito de todos. Sendo assim, vê-se que há muito o que melhorar.

Falando mais especificamente do Instituto Federal de Educação, Ciência e Tecnologia do Rio Grande do Norte (IFRN) campus Natal - Central (CNAT), detalharemos a seguir alguns aspectos contidos na instituição com relação à inclusão. No início deste ano, o CNAT recebeu cinquenta alunos com Necessidades Educacionais Específicas (NEE), no entanto, não possui estrutura suficiente para atender a todos, tanto no que se refere à pequena quantidade de equipamentos de assistência como ao fato de alguns professores se sentirem despreparados para lecionar a alguém com NEE.

Neste cenário, insere-se a monitoria, um projeto proposto pelo Núcleo de Apoio às Pessoas com Necessidades Educacionais Específicas (NAPNE) do IFRN, que tem como objetivo contribuir para a inclusão desses alunos no IFRN. Vale ressaltar no presente trabalho que estamos fazendo referência apenas à monitoria do conteúdo de Matemática.

Entendemos por monitoria o acompanhamento rotineiro, de modo sistemático, que visa o aprendizado concreto de pessoas que possuem dificuldades em determinados conteúdos acadêmicos. Esse acompanhamento promove um esclarecimento de assuntos para o aluno com deficiência, como também é uma experiência enriquecedora para o monitor, estando este em um curso de formação de professores, que o ajudará a lidar melhor com os desafios que encontrará no futuro quando estiver atuando já como um profissional.

Dentre os vários tipos de deficiência (visual, auditiva, mental, física, múltipla), iremos nos dedicar aqui apenas à visual, pois o trabalho que estamos desenvolvendo no IFRN é com uma aluna com essa deficiência. O nome real dessa aluna será preservado e usaremos o pseudônimo Maria. 


\title{
FUNDAMENTAÇÃO TEÓRICA
}

Incluir os alunos com deficiência visual, ou outras necessidades educativas específicas requer da escola e do sistema

\begin{abstract}
ao qual ela está vinculada, pensar em políticas, projetos, ações e práticas pedagógicas que realmente possam torná-la competente para que essa inclusão não represente apenas a matrícula escolar. Torna-se, assim, necessário que essa escola, que historicamente nunca foi para todos, caminhe no sentido de efetivamente incluir todos os diferentes, garantindo-lhes o acesso, a permanência, participação e a efetiva aprendizagem e desenvolvimento (KRAZ, 2015, p.10)
\end{abstract}

Em se tratando de Matemática, se faz ainda mais necessário a atuação de graduandos em uma monitoria para oferecer suporte aos estudantes da instituição, haja vista que, segundo Silva et al (2013, p. 1), tal disciplina provoca elevados níveis de reprovação, o que contribui para o fracasso escolar. Essa situação é ainda mais preocupante quando consideramos que, dentro desse contexto, também estão os alunos com deficiência, os quais possuem um nível maior de dificuldade devido às suas respectivas condições e a falta de investimento na aprendizagem desses discentes.

Para proporcionar o aprendizado dos alunos com deficiência visual são necessárias adequações, como o uso de material concreto para que possam ter acesso ao conhecimento por meio dos sentidos remanescentes.

A respeito da utilização de material concreto, Fortes (2017, p. 137),

o uso de materiais concretos e tridimensionais também é interessante, dentre eles o
geoplano, figuras geométricas tridimensionais e multiplano. Além desses existe o
Sorobã, o Tangran, o Material Dourado, o Disco de Fração entre outros materiais
concretos, que podem ser utilizados durante as aulas de Matemática, no intuito de
contribuir para o melhor desenvolvimento das atividades propostas.

Sendo assim, o uso do material concreto torna-se pertinente para o aprendizado do aluno, e por isso tem sido utilizado, de forma mais sistemática, durante as aulas de monitoria em Matemática.

\section{METODOLOGIA}

$\mathrm{O}$ projeto de pesquisa na área da monitoria baseia-se numa pesquisa qualitativa e numa pesquisa-ação, que nos direcionou para o desenvolvimento de três fases. A primeira corresponde a fase exploratória em que buscamos, por meio da entrevista com os professores de Matemática, conhecer as necessidades de cada aluno com necessidades educativas específicas, principalmente em relação à aluna cega.

Após esse momento, marcamos reuniões para traçarmos os planos de ação para cada monitor, bem como as orientações para as coletas dos dados que ocorreriam no decorrer das 
aulas de monitoria por meio do diário de campo.

O método da monitoria se baseia em um momento em que ocorre um aprofundamento do conhecimento adquirido por Maria, aluna do curso de Licenciatura em Geografia, em sala de aula. Isso facilita a compreensão dos conteúdos e exercícios feitos por seus professores. A monitoria vem como uma oportunidade de nós, enquanto monitores, darmos suporte a alunos com necessidades educacionais específicas. Tal suporte acontece às terças-feiras, das $14 \mathrm{~h} 30$ às $17 \mathrm{~h} 00$.

É um momento em que tentamos deixar o aprendizado mais tátil possível, trazendo jogos e peças que ajudem a solidificar os conceitos absorvidos. Os assuntos que estão sendo abordados são da disciplina de Estatística, dentre eles: conceitos básicos da Estatística, gráficos e tabelas, Probabilidade, etc. Além disso, aplicamos um jogo chamado Torre de Hanói para trabalhar o desenvolvimento de estratégias e o raciocínio lógico da aluna. Também levamos o Geoplano e uma prancheta de desenho em relevo para que ela pudesse conhecer as formas dos tipos de gráficos.

Podemos observar essas estratégias nas fotos a seguir:

Foto 01: monitor Thiago em atividade com a aluna Maria utilizando a Torre de Hanói

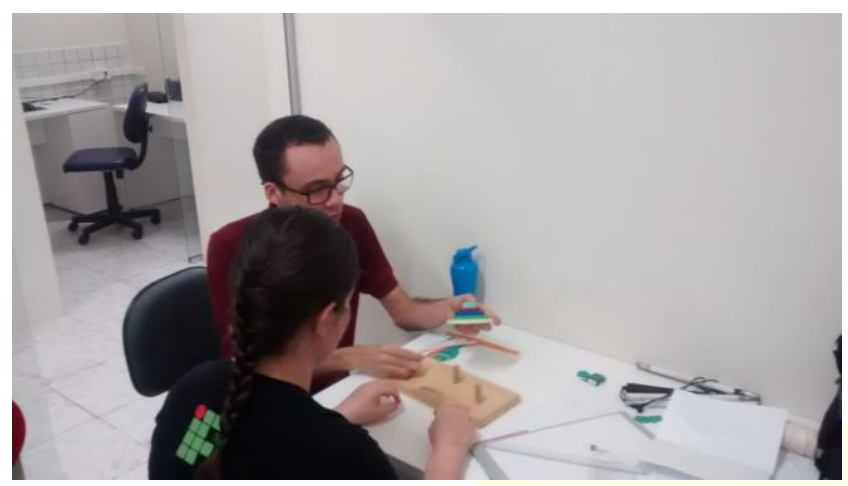

Foto 2: monitor Leandro em atividade com a aluna Maria.

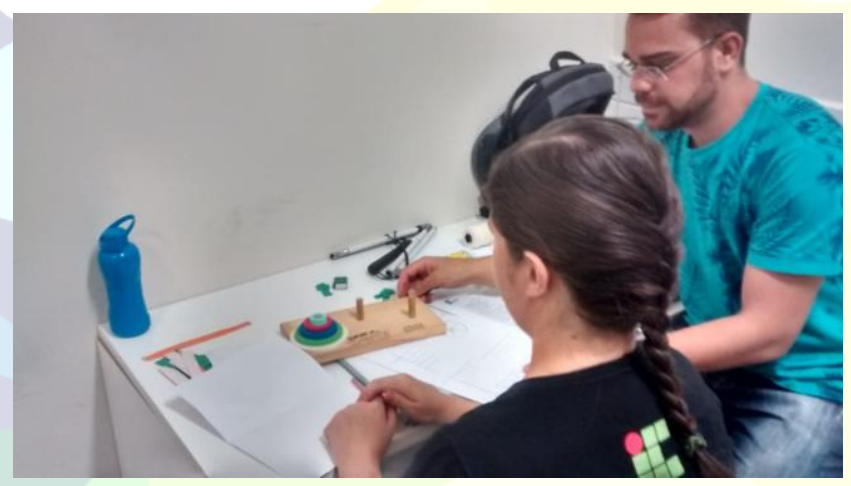

\section{RESULTADOS E DISCUSSÕES}

A monitoria tem se tornado algo bem prazeroso e de grande aprendizado para a aluna 
cega e para os monitores, facilitando o processo de inclusão, pois Maria tem consolidado os temas abordados em sala de aula e entendido melhor os exercícios, pois utilizamos uma abordagem mais pessoal e utilizamos materiais mais concretos com foco em suprir a necessidade educacional específica da aluna. Já para os monitores, tem sido uma experiência bastante significativa, já que tem proporcionado uma bagagem enriquecedora e única para atuar na futura profissão.

\section{CONCLUSÕES}

Acreditamos que é tarefa da escola ser um espaço fundamental à aprendizagem do conhecimento científico construído e acumulado pela humanidade, bem como proporcionar um ambiente propício para isso e ao qual todos possam ter acesso. A nossa própria Constituição garante educação para todos. Porém, não é isto que está acontecendo. O que notamos é mais um cenário de exclusão do que um ambiente inclusivo, ou seja, nem todos estão tendo como acessar uma educação de qualidade. Logo, temos muito a melhorar.

Nesse caminho em buscar incluir - de forma significativa - os alunos com deficiência visual, a monitoria tem possibilitado o direito de aprender desses discentes, minimizando as dificuldades em sala de aula, como também tem sido um aporte para os professores, para a instituição e para os licenciados/monitores.

\section{REFERÊNCIAS}

BRASIL. Constituição (1988). Constituição da República Federativa do Brasil. Brasília, DF: Senado Federal: Centro Gráfico, 1988. 292 p.

FORTES, Vanessa Gosson Gadelha de Freitas Fortes. Formação continuada de professores do Ensino Médio Integrado do Instituto Federal de Educação, Ciência e Tecnologia do Rio Grande do Norte (IFRN), na perspectiva da inclusão escolar de aluno com deficiência visual. Tese. Universidade Federal do Rio Grande do Norte. Programa de PósGraduação em Educação. Natal, 2017.

KRANZ, Cláudia R. O Desenho Universal na Educação Matemática Inclusiva. In: XIV Congresso Internacional de Educação Matemática - CIAEM-IACME. Chiapas, México, 2015. Disponível em: http://xiv.ciaemredumate.org/index.php/xiv_ciaem/xiv_ciaem/paper/viewFile/1371/528. Acessado em: 14.set.18. 